\title{
Sentidos produzidos acerca do consumo de substâncias psicoativas por usuários de um Programa Público
}

\section{The meaning of illicit drug usage in patients of a Public Prevention Program}

Miranice Nunes dos Santos Crives

Assistente Social da Secretaria Municipal de Saúde de Natal/RN, Especialista em Saúde Pública, Mestranda em Serviço Social na UFRN.

E-mail: miracrivesळufrnet.br

\section{Magda Dimenstein}

Psicóloga, Doutora em Saúde Mental pelo IPUB/UFRJ, Profa. do Programa de Pós-Graduação em Psicologia da UFRN.

\section{Resumo}

Este trabalho objetiva discutir os sentidos produzidos acerca do consumo de substâncias psicoativas por usuários do Programa de Prevenção e Tratamento de Alcoolismo e outras Dependências, implantado, em 1993, no ambulatório do Centro de Saúde de Pirangi da Secretaria Municipal de Saúde de Natal/RN. Foram realizadas 14 entrevistas com usuários de quatro categorias: em tratamento; de alta; os que entraram no programa de forma voluntária; os que entraram de forma compulsória. As falas foram analisadas segundo a perspectiva da análise do discurso. Os resultados indicam que as substâncias mais consumidas são o álcool e a maconha. Os fatores motivadores do uso de drogas são: a) fuga dos problemas; b) curiosidade; c) influência dos amigos; d) insatisfação com a vida; e) busca de prazer e fraqueza pessoal; sinalizando a complexidade e a multideterminação do uso de drogas. O uso de drogas, para os usuários, apresenta tanto um sentido negativo, associado aos danos físicos e sociais decorrentes do uso, quanto um sentido positivo, relacionado com a sensação de bem-estar sentida e "esquecimento" e fuga dos problemas. Outro aspecto observado nas entrevistas revela representações construídas socialmente em torno das pessoas que usam drogas, tidas como "marginais", "fora da lei", prevalecendo uma visão punitiva e discriminatória da questão.

Palavras-Chaves: Produção de sentido, Uso de drogas, Usuários, Programa público 


\section{Abstract}

The purpose of the study was to identify the meaning of drug consumption in patients of the Alcohol and Drug Prevention and Treatment Program at the Pirangi Health Center in Natal, RN. Fourteen interviews were conducted with drug users who were under, or had been released from treatment, and that were in the program voluntarily or by court order. Discourse analysis of the data showed that alcohol and marijuana were the most common drugs used and that the major motivating factors were: a) to escape from problems; b) curiosity; c) the influence of friends; d) dissatisfaction with life; e) pleasure, and f) personal weakness, confirming the multi-determinism and the complexity of the problem. The use of drugs to these clients had both a negative meaning associated with physical and social consequences, and a positive one related to a feeling of well-being and of "forgetting" problems. These socially constructed representations originate in a context where the user of drugs is seen as a "marginal" or a "delinquent" person, thereby imposing a punitive and discriminatory perspective on the problem.

Key Terms: Meaning, Drug Addiction, Drug Users, Public Program

\section{Introdução}

Neste artigo discutiremos parte dos resultados de uma pesquisa realizada junto aos usuários de um Programa de Prevenção e Tratamento de Alcoolismo e outras Dependências, desenvolvido no ambulatório no Centro de Saúde de Pirangi da Secretaria Municipal de Saúde de Natal/RN a partir de 1993. A pesquisa teve por objetivo analisar a qualidade das ações deste serviço público, na perspectiva de seus usuários. Neste artigo limitaremos nossa discussão e análise a um dos aspectos investigados: os sentidos produzidos pelos usuários a respeito do uso de drogas.

Para termos uma maior compreensão sobre a realidade onde se inseriu a nossa pesquisa, situaremos, de forma breve, o contexto sócio-político na década de 9o, que ancorou e influenciou a política institucional pública na área da dependência química no Brasil, particularmente em Natal/RN no âmbito da Secretaria Municipal de Saúde, situando particularmente o Programa de Prevenção e Tratamento de Alcoolismo e outras Dependências, precedido de uma contextualização das drogas na nossa sociedade.

\section{O Uso de Drogas na História e o Contexto das Po- líticas Públicas de Saúde}

O uso de drogas na história da humanidade é uma prática milenar e universal. 0 homem, nas diversas culturas, sociedades e épocas sempre consumiu drogas o que, na maioria das vezes, não se constituiu em problemas e motivos para alarmes sociais, sendo consumidas com finalidades religiosas, terapêuticas e lúdicas, sendo entendida como uma manifestação cultural e humana (Brasil, 1999). Substâncias como o café, as bebidas alcoólicas, a cocaína, o rapé e derivados da cannabis, segundo Bastos e Cotrim (1998), estiveram e ainda estão presentes nas cerimônias religiosas e em medicamentos caseiros, dentre outros.

Entretanto, nas últimas décadas, indicadores apontam que esse consumo tem tomado dimensões preocupantes, tendo graves conseqüências, principalmente para os jovens e adultos jovens, expressandose nas várias interfaces da vida cotidiana, como por exemplo em relação à família, comprometendo vínculos afetivos, no trabalho, no trânsito, na saúde, e in- 
clusive, na disseminação do vírus HIV¹ (Brasil, 1999). Diversos danos secundários ao consumo abusivo de substâncias psicoativas foram ressaltados por Bastos e Cotrim (1998), a saber: acidentes de trânsito, overdoses, envenenamentos, doenças cardiorespiratórias e a violência decorrente da ação farmacológica dos produtos: brigas, homicídios, furtos e roubos, entre outros.

A problemática do uso abusivo de drogas enfrenta também outras questões importantes, dentre elas merece destaque os interesses econômicos² que envolvem a produção e venda de drogas, sejam elas lícitas $^{5}$ ou ilícitas; embates de cunho moral e ideológico, somados à falta ou a pouca prioridade política dos governos, que se manifesta na insuficiência de recursos financeiros necessários para garantir efetivamente uma política de educação, prevenção e tratamento, com recursos humanos capacitados continuamente e pagos adequadamente. Além disso, as precárias condições de trabalho e de materiais necessários para o tratamento e assistência às necessidades e problemas dos usuários de drogas são uma realidade no país.

0 incremento do uso de drogas vem sendo associado à situação de vulnerabilidade social vivida por alguns grupos, bem como à cultura do consumo pregnante em nossa sociedade. Sobre o primeiro aspecto, considera-se que ampla parcela da sociedade vive permanentemente ameaçada pela instabilidade de suas condições de vida e pela exclusão social. Segundo Zaluar (1994), o estado de miséria social e o desamparo político têm acarretado novas estratégias de sobrevivência, dentre as quais está a entrada cada vez maior de jovens no mundo do tráfico. A questão da exclusão social, por sua vez, refere-se não só aos grupos economicamente desfavorecidos, mas a toda uma parcela da sociedade que se encontra em situação de "inutilidade social" ou de "exclusão existencial”, que atinge tanto pobres, quanto ricos de forma violenta, na medida em aponta para a ausência de valores identi- tários, para uma crise de significações do imaginário social (Waiselfisz,1998).

De acordo com Silveira e Silveira (1999), embora a maioria dos jovens seja contrário ao uso das drogas, muitos se deixam levar pela chamada "pressão do grupo" e acabam envolvendo-se com algum tipo de consumo. Além da pressão do grupo, continuam os autores, "existe ainda a pressão exercida pelo consumo que tem na busca do prazer um dos valores mais cultivados na sociedade moderna" (p.74).

Sabemos que as políticas públicas predominantes em relação ao consumo de drogas em muitos países, inclusive no Brasil, têm privilegiado, na maioria das vezes, o caráter coercitivo e punitivo, ou seja, uma postura centrada na repressão em relação à produção e ao consumo de substâncias ilícitas, como se fosse possível tratar a questão das drogas como um mero "caso de polícia”. Esta perspectiva de análise foi reconhecida pelo $1^{\circ}$ Fórum Nacional Anti-Drogas realizado em 1998, do qual o governo brasileiro participou na condição de um dos realizadores, através da Secretaria Nacional Anti-Drogas (SENAD). O relatório deste evento importante fez a seguinte afirmação:

“...pouco se fez no campo da prevenção através da educação para a saúde. Paralelamente, as drogas lícitas, em particular o álcool e o tabaco, não mereceram nenhuma atenção e até foram alçadas, através da publicidade, à condição de promotoras do sucesso, poder, bom gosto e finesse". (Brasil,1998, p.12)

Ainda conforme o citado relatório, constata-se, por um lado, as contradições, as insuficientes e inadequadas medidas e ações desenvolvidas pelas políticas públicas brasileiras, e, por outro lado, a maioria dos meios de comunicação faz uso do termo droga, com algumas poucas exceções, para divulgação de fatos referentes às drogas ilícitas, ao passo que, em relação às drogas lícitas, pouco tem sido mostrado acerca dos inúmeros problemas que envolvem o uso abusivo dessas drogas, apesar de mais danoso para a saúde pública.

\footnotetext{
1 No Brasil por volta de $25 \%$ dos casos de AIDS que são notificados no Ministério da Saúde estão relacionados ao uso de drogas injetáveis. Em 1982 foi registrado o primeiro caso de AIDS entre usuários de drogas injetáveis, sendo que em 1985 este número representava $2,7 \%$ do total (14 casos), já em 1990 chega a 18,2\% (736 casos). Sobre essa questão ver o documento denominado: Elaboração de Proposta para Normalização de Serviços de Atenção a Transtornos por Uso e Abuso de Substância Psicoativa, da Coordenação de Saúde Mental. MS, 1998.

2 Segundo Antônio Caballero, jornalista colombiano, os verdadeiros motivos da proibição da droga não são nem científicos nem morais. Os motivos são econômicos e políticos. Graças à proibição, as drogas geram muito dinheiro e, como conseqüência, grande poder. Os grupos ou setores que se beneficiam, ainda conforme o citado autor, são os seguintes: narcotraficantes; as guerrilhas; os serviços secretos e os aparatos militares; os próprios governos e os bancos (Caballero,1994).
} 
De acordo com Vara (1998), os diversos modelos de intervenção nos casos de uso e abuso de substâncias passíveis de causar dependência, estão relacionados à seguinte questão: é possível uma sociedade livre de todas as drogas? Se se parte de uma perspectiva positiva, é possível compreender as políticas internacionais e nacionais voltadas para reduzir a comercialização, distribuição e consumo dessas substâncias, as quais terminam penalizando o usuário, estimulando o enriquecimento ilícito e a organização do crime, potencializando os sistemas policiais, judiciais e penitenciários. Se se considera que não há possibilidade de uma sociedade que não faça uso de psicoativos, uma perspectiva, então, volta-se para a redução de danos, sejam individuais ou coletivos.

"Pensar en reducir los daños y/o los riesgos, potencia el trabajar sobre la demanda de drogas tanto, almenos, como sobre su oferta. Supone apoyar modificaciones legales que no penalicen desproporcionadamente más al abusador usuario que al traficante del producto ilegal. Supone reconsiderar la condición del usuario que, en algunos niveles de deterioro relacionado con el consumo, cumple con creces los criterios de una enfermedad crónica recidivante y, además, por ello, permite encajar su situación en el marco de la Salud Pública” (p.12)

Esse ponto de vista implica numa percepção das drogas como produto sócio-cultural e seu uso multideterminado. Afasta-se também de uma posição puritana, moralista, que não consegue avançar em termos do desenvolvimento de alternativas de intervenção que levem em consideração as demandas de uma sociedade consumista, narcísica e hedonista, onde a droga ocupa um lugar especial de "solução mágica", de alívio do mal-estar produzido nas relações cotidianas. Nesse sentido, as drogas podem ser entendidas como bens simbólicos, carregando em si a promessa de felicidade garantida e de fácil acesso.

Na perspectiva de mudança do quadro das políticas públicas no Brasil em relação à complexa problemática do uso abusivo de drogas, há alguns sinais positivos que se expressam na criação de novos serviços de saúde, apesar de ainda bastante incipientes, enquanto resultado de um processo de lutas sociais e políticas, que se expressam em fóruns, centros de estudos e pesquisas, serviços e programas públicos, etc voltados para minimizar essa realidade, na qual se insere o Programa de Prevenção e Tratamento de Álcool e outras Drogas do Centro de Saúde de Pirangi em Natal/RN.

Ao final da década de 8o, e ao longo dos anos 9o, o setor saúde ganhou realce no cenário das políticas públicas no Brasil, tendo sido coroado com a criação do Sistema Único de Saúde (SUS), inscrito na Constituição Brasileira de 1988, com o reconhecimento da saúde enquanto um direito de cidadania e dever do Estado, associada às condições de vida.

Nesse contexto, se insere o processo de Reforma Psiquiátrica Brasileira, que teve seu inicio, conforme Amarante (1995:51), no período compreendido entre o final de década de 70 e início dos anos 80. Os objetivos principais da Reforma Psiquiátrica, entendida aqui como um processo sócio-histórico, vem sendo a busca de novas premissas teórico-conceituais, técnicoassistenciais, político-jurídicas, sócio-culturais, metodológicas e éticas para a assistência psiquiátrica no Brasil, contrapondo-se de forma crítica e prática ao modelo assistencial clássico de atenção à saúde mental dominante, centrado no hospital psiquiátrico (Brasil, 1994).

Nesta trajetória destaca-se a realização da I Conferência Nacional de Saúde Mental em 1987, reafirmando a falência do modelo asilar e impulsionando movimentos de reforma na área. Dois anos mais tarde realizou-se a Conferência de Caracas na Venezuela, cujo objetivo principal foi a reestruturação da assistência psiquiátrica na América Latina, constituindose em uma referência fundamental para o processo de transformação do modelo de atenção à saúde mental no Brasil (Brasil, 1998). Essa Conferência, "marca o fim da trajetória sanitarista e o início de uma outra: a trajetória da desinstitucionalização ou desconstrução/invenção" trazendo ao cenário político novos atores de saúde mental: "são os loucos, os loucos pela vida" (Amarante,1995:93-95).

Avançando nessa direção, foram traçadas as linhas principais da reorientação da saúde mental durante a II Conferência Nacional de Saúde Mental em 1992, cujas deliberações tiveram papel importante sobre os rumos da Reforma Psiquiátrica na década de 9o, principalmente sobre a construção de uma rede de atenção à saúde mental, sobre a transformação da legislação e do direito à atenção integral e à cidadania, visando substituir progressivamente o modelo 
hegemônico de assistência psiquiátrica.

Nessa perspectiva, surgiram novos serviços de saúde mental, ganhando destaque os Núcleos de Atenção Psicossocial (NAPS) e Centros de Atenção Psicossocial (CAPS), serviços de nível intermediário, cuja proposta de trabalho, via de regra, estão voltadas para o tratamento de portadores de psicoses e neuroses graves e de usuários de álcool e/ou outras drogas respectivamente. Estes serviços estão organizados e desenvolvidos a partir das seguintes diretrizes: universalidade, hierarquização, regionalização, integralidade das ações; diversidade de métodos terapêuticos; trabalho por equipes multiprofissionais e participação social, conforme normas estabelecidas pelo Ministério da Saúde através da portaria nº 224/92.

Neste processo, merece destacar também o projeto de lei 3.657/89 do deputado federal Paulo Delgado (PT de Minas Gerais), aprovado somente em abril de 2001, sendo transformada na Lei 10.216 de 06 de abril de 2001, que ficou conhecida como a "lei da reforma psiquiátrica”. Esta lei estimulou e possibilitou o debate sobre o atual modelo de assistência psiquiatrica e os direitos das pessoas portadores de transtornos mentais em todo o Brasil, inclusive influenciando o surgimento de novas leis em nível estadual e municipal, inclusive no Rio Grande do Norte.

No município de Natal, estas transformações político-institucionais nacionais, entre outras, impulsionaram e influenciaram um movimento de um grupo de trabalhadores da saúde do município de Natal aliados a sanitaristas e profissionais da UFRN (Universidade Federal do Rio Grande do Norte), que já atuavam nesta área, os quais passaram a reivindicar da Secretaria Municipal de Saúde (SMS) de Natal, investimentos institucionais técnicos, político-administrativos e financeiros na perspectiva da construção de uma política de saúde mental e da implantação de serviços na perspectiva reformista. Após muitas articulações, encontros, debates, negociações, inclusive institucionais, este movimento, aliado à conjuntura política, teve como resultado a implantação em Natal, em meados da década de 9o, de dois NAPS (Núcleo de Atenção Psicossocial), destinado a pessoas com transtornos mentais; um CAPS (Centro de Atenção Psicossocial) e um Programa, em nível ambulatorial, ambos destinados a usuários com problemas de dependência de álcool e/ou outras drogas.
O mencionado Programa de Prevenção e Tratamento de Alcoolismo e outras Dependências, objeto de nossa investigação original, foi criado em 1993 no Centro de Saúde de Pirangi, localizado no Distrito Sanitário Sul de Natal, capital do RN, sendo pioneiro na assistência à dependência química na rede pública de saúde municipal. Seu principal objetivo é "contribuir para abstinência do uso abusivo de álcool e outras drogas na perspectiva da melhoria da qualidade de vida" e a atividade terapêutica predominante é grupoterapia e/ ou grupo operativo (Natal, 1999). Outra atividade realizada pelos profissionais é o "Grupo de Familiares" do qual participa, de forma voluntária, uma pessoa da família que seja próxima do usuário em tratamento, sendo coordenado por um profissional de serviço social, com o objetivo de refletir sobre a problemática que envolve o uso abusivo de álcool e outras drogas, bem como as dificuldades e possibilidades da família para enfrentar a questão sem preconceitos.

Soma-se a isso, outras ações que os profissionais também desenvolvem na área de promoção e educação em saúde através de seminários, reuniões, palestras e atividades sócio-recreativas, além de atividades interinstitucionais destinadas aos usuários e familiares, estudantes e pessoas interessadas na temática. O Programa vinculado à Coordenação de Saúde Mental da Secretaria Municipal de Saúde, contava no período da pesquisa de campo com uma equipe técnica multiprofissional composta por um médico clínico geral, que exercia a função de coordenador, duas assistentes sociais, uma psicóloga.

Conforme o livro de registro dos usuários no Programa, foram inscritos até agosto de 2000 com um total de 342 (trezentos e quarenta e dois) usuários, que ingressaram no tratamento de forma voluntária e compulsória, que ocorre neste último caso, quando a justiça determina o ingresso no tratamento (Crives, 2001). O tempo de tratamento no Programa é de um ano, sendo que o usuário pode receber alta antes desse período, como também pode permanecer por mais tempo, dependendo de sua "evolução" no tratamento, a qual é avaliada pelos profissionais de referência do grupo. Esta avaliação leva em consideração, principalmente, os objetivos do Programa, os quais são de conhecimento dos usuários, além das características e necessidades individuais de cada usuário e dados que indiquem a sua melhoria da qualidade de vida. 


\section{Procedimentos Metodológicos da}

\section{Pesquisa}

Essa investigação caracteriza-se como de natureza qualitativa, uma vez que procuramos privilegiar e apreender a percepção, os valores, expectativas dos usuários a respeito do uso de drogas e do programa de atenção. Partindo do entendimento de que a pesquisa qualitativa exige um instrumental de coleta que seja capaz de apreender as múltiplas dimensões do objeto pesquisado, elaboramos um roteiro de entrevista semi-estruturado ancorado nos seguintes eixos: caracterização sócio-econômica; acessibilidade, satisfação e resolutividade do programa, concepções sobre o uso de drogas e avaliação da interação profissionalusuário. Contudo, como já foi referido anteriormente, discutiremos apenas o discurso dos usuários sobre o uso das drogas, aspecto esse que atravessou vários eixos da pesquisa.

Foram entrevistados individualmente 14 (catorze) usuários no período de julho a agosto de 200o, selecionados a partir dos seguintes critérios:

1. Ter ingressado no programa de forma voluntária e ter recebido alta após um ano de tratamento (o4 usuários).

2. Ter ingressado no programa de forma voluntária e estar em tratamento há seis meses (o3 usuários).

3. Ter ingressado no programa de forma compulsória e ter recebido alta, após um ano de tratamento (o3 usuários).

4. Ter ingressado no programa de forma compulsória e estar em tratamento há seis meses (o4 usuários).

Apesar de não ter estabelecido uma análise comparativa entre os usuários que ingressaram no tratamento de forma voluntária ou compulsória, entendemos que seria importante e necessário contemplar no grupo de atores participantes da pesquisa os dois "tipos” de usuários do programa, tendo em vista observar importantes diferenças e semelhanças de opiniões acerca do uso de substâncias psicoativas.

É importante esclarecer que delimitamos o prazo mínimo de seis meses para os usuários em tratamento, considerando que o nosso estudo de perspectiva qualitativa exigia um período razoável de permanência no Programa para que os entrevistados pudessem ter condições de expressarem suas percepções em re- lação aos seus objetivos, funcionamento e dinâmica, mas, sobretudo, sobre a qualidade das ações desenvolvidas. O tempo de o1 (um) ano de tratamento foi estabelecido para aqueles que realizaram tratamento e receberam alta do tratamento. As entrevistas foram gravadas com o consentimento dos usuários, e por uma questão ética de sigilo, foram identificadas com as seguintes abreviaturas:

a) UTVA (Usuário Tratamento Voluntário Alta);

b) UTV (Usuário em Tratamento Voluntário);

c) UTCA (Usuário Tratamento Compulsório Alta);

d) UTC (Usuário em Tratamento Compulsório).

Em seguida, acrescentamos (F) para feminino e (M) para masculino, e por último, a sua idade. Além da técnica da entrevista, utilizamos também documentos institucionais. Em relação à análise dos dados optamos pela técnica da análise temática, o que nos possibilitou organizar e interpretar os dados da seguinte forma: as entrevistas foram transcritas, e em seguida, realizadas várias leituras. Posteriormente, organizamos o material em categorias considerando os objetivos do trabalho, etapa que parece identificada à “constituição do corpus" (Minayo, 1992). Por último, procuramos apreender o núcleo das falas dos usuários ancorada em aporte teórico e também a experiência vivenciada no Programa pela pesquisadora deste estudo.

\section{Apresentação e Discussão dos Resultados da Pesquisa}

\section{Perfil dos usuários}

Sexo: a maioria é do sexo masculino, correspondente a $71 \%$ dos entrevistados desta pesquisa. Esse resultado assemelha-se ao encontrado no levantamento realizado pelos profissionais do Programa no biênio 97/98.

De acordo com o DATASUS/MS, os registros de morbidade hospitalar do SUS/CID-10, em Natal, no período de janeiro de 1988 a julho de 2000 , apontaram um total de 18 mulheres na faixa etária de 20 a 29 anos, internadas com o diagnóstico de "transtornos mentais e comportamentais devido o uso de outras substâncias psicoativas". Enquanto que, nesse mesmo período e com o mesmo diagnóstico, foram internados em Natal 17o homens na mesma faixa etária. 
Idade: Predominam as faixas etárias de 20 a 29 anos (o6 homens) e de 30 a 39 anos (o2 homens e 02 mulheres). Esse resultado coincide com os achados anteriores do referido Programa, revelando que se trata de uma população de adultos jovens que está numa fase de vida caracterizada como economicamente ativa, constituindo-se em momento de fortes cobranças em relação à formação profissional e independência financeira. Enfim, um ciclo da vida caracterizado por pressões externas e internas na busca de definições de papéis sociais, na vida familiar e afetiva, que podem contribuir para a busca de "amparo" nas drogas. Entretanto, as pesquisas do Centro Brasileiro de Informações sobre Drogas Psicotrópicas CEBRID/ UNIFESP realizadas com estudantes de $1^{\circ}$ e $2^{\circ}$ graus, crianças e adolescentes, confirmam uma tendência mundial que aponta na direção da iniciação cada vez mais precoce e de forma mais pesada no uso abusivo de drogas, manifestando um aspecto importante e preocupante em relação ao enfrentamento da problemática das drogas (Brasil, 1998).

Escolaridade: A maior parte dos usuários (35,7\%, n = 5) tem apenas $01^{\circ}$ grau incompleto, seguido de $21,4 \%$ $(\mathrm{n}=4) \mathrm{com} \mathrm{o} 1^{\mathrm{o}}$ grau completo. Dois usuários $(14,3 \%)$ têm o $2^{\circ}$ grau incompleto e dois (14,3\%) têm $3^{\circ}$ grau incompleto. Apenas um entrevistado tem o $2^{\circ}$ grau completo, bem como o $3^{\circ}$ grau incompleto $(n=1)$. Tais dados revelam um baixo nível de escolaridade entre os usuários.

As poucas mulheres detêm um nível de escolarização mais alto em relação aos homens. Alguns entrevistados afirmaram em seus relatos que deixaram de estudar em decorrência das precárias condições de vida a que estavam submetidos, sendo obrigados a disponibilizarem seu tempo em busca de trabalho para garantir a sua sobrevivência e da sua família em detrimento de continuar na escola.

Situação Conjugal: A metade dos usuários é solteira (50\%), vivendo com seus pais e irmãos ou avós, porém, uma parte deles já teve filhos com suas ex-companheiras ou namoradas. Todos os entrevistados relataram conflitos sejam em relação ao casamento, aos filhos e aos pais, problemas de violência doméstica, dentre outros, em decorrência, principalmente, do uso abusivo de drogas, mas também em função dos problemas financeiros.
Ocupação: Quase todas as mulheres que realizam tratamento no Programa, que são minoria no Programa, são donas de casa. Dentre os homens, predominam os pequenos bicos, portanto, estão inseridos no mercado informal de trabalho, ou seja, em ocupações que não exigem qualificação profissional. Esses usuários encontram-se numa situação de trabalho temporário, expostos a uma condição de vulnerabilidade, o que vem afetando sua qualidade de vida e de sua família. Renda: A distribuição de renda entre os usuários revelou dados preocupantes. Do total dos usuários, (14,3 $\%, n=2)$ não têm nenhuma renda e $(21,4 \%, n=3)$ percebem menos de um salário mínimo (SM) vigente na época da pesquisa, e igual percentual percebe de 1 a 2 SM. Daqueles que ganham de 1 até 3 SM (50\%), a maioria não tem carteira de trabalho assinada, e conseqüentemente sem direitos trabalhistas assegurados, prevalecendo um nível de renda muito baixo para garantir as necessidades básicas de alimentação, moradia e transporte, conforme já sinalizavam outros dados do perfil.

\section{Motivos de ingresso dos usuários no Programa}

Do total de 14 (catorze) usuários entrevistados nesta pesquisa, a metade ingressou voluntariamente no tratamento, cujos motivos deste ingresso estão relacionados, principalmente, ao desejo de parar ou reduzir o uso abusivo de álcool e/ou outras drogas. A busca voluntária destes usuários pelo tratamento, acontece em geral, no momento em que eles reconhecem que o uso abusivo de álcool e/ou outras drogas se torna desconfortável e apresentam problemas difíceis de serem manejados, trazendo conseqüências para a saúde, para o trabalho, mas, sobretudo, em relação à família, fazendo sofrer pessoas a quem ama, o que por si só, representa um motivo importante para tentar deixar de usar drogas, na opinião desses entrevistados.

Os demais usuários $(\mathrm{n}=7$ ) foram encaminhados compulsoriamente pela $9^{\text {a }}$ Vara Criminal da Comarca de Natal/RN, em função de terem sido flagrados usando drogas consideradas legalmente ilícitas. Quase todos esses usuários chegam revoltados ao programa com a imposição da justiça, uma vez que não se sentem usuários abusivos de drogas, e diferentemente dos usuários voluntários, não atribuem às drogas os mesmos problemas anteriormente citados. Nesse sen- 
tido, manifestam muitas resistências e dificuldades de realizarem o tratamento, há uma clara dificuldade em termos de sua adesão e conseqüentemente parte deles abandona o tratamento. Todavia, é necessário dizer que, apesar da imposição da justiça, uma pequena parte destes usuários, com o decorrer do tratamento, consegue participar e reconhecer as contribuições do programa, principalmente em relação à mudança de lugar das drogas em suas vidas.

A seguir apresentaremos os resultados referentes às drogas consumidas pelos usuários entrevistados, bem como suas percepções sobre o uso das mesmas.

\section{Tipos de drogas consumidas pelos entrevistados}

\section{Quadro I: Distribuição das drogas, segundo o consumo dos entrevistados}

\begin{tabular}{|l|c|}
\hline Drogas & Número de usuários \\
\hline Álcool & 7 \\
\hline Maconha & 7 \\
\hline Cocaína & 6 \\
\hline Tabaco & 5 \\
\hline Medicamentos Psicotrópicos & 5 \\
\hline Crack & 3 \\
\hline Cola de sapateiro & 2 \\
\hline Outras & 1 \\
\hline
\end{tabular}

Fonte: pesquisa direta com usuários do PPTAD/2000

Observa-se a partir do quadro acima, que as drogas mais consumidas pela metade dos entrevistados são o álcool e a maconha que aparecem igualmente na primeira posição, sendo referidas por usuários em tratamento e de alta. Isso demonstra que o consumo de drogas lícitas, como o álcool, é bastante significativo no contexto local, coincidindo com os estudos realizados no Brasil, que mostram o álcool como a droga mais consumida e a responsável pelos maiores problemas decorrentes do uso abusivo (Bastos e Cotrim, 1998; Noto e col, 1999).

Interessante notar que no cenário epidemiológico brasileiro envolvendo as drogas, embora se perceba que vem ocorrendo um aumento do uso de drogas ilícitas, são as drogas legais que representam mais de 90\% dos abusos e usos freqüentes praticado pela população, representando um custo social bastante alto (Brasil, 1998).

Para se ter uma idéia, em termos de mortalidade, o abuso de álcool e fumo é responsável por cerca de 95\% dos casos de óbito associados a essas drogas, sendo que somente $5 \%$ são imputadas às "outras drogas" no seu conjunto (Bucher, 1994, p.35). Contudo, em que pese essa situação, as maiores preocupações do governo, da mídia, das autoridades, familiares e da sociedade, de um modo geral, recaem sobre as chamadas drogas ilícitas.

Ainda de acordo com o quadro apresentado, observa-se que a maconha aparece numa posição igual a do álcool entre os entrevistados. Este resultado sugere que há um acesso relativamente fácil do usuário ao produto, bem como aponta uma certa banalização na medida em que é uma droga que parece fazer parte do cotidiano das pessoas tal qual o álcool. A cocaína aparece em seguida, sendo referida por quase todos os usuários em tratamento compulsório. 0 tabaco $^{3}$ e as medicações psicotrópicas foram citados por todos os usuários igualmente. Finalmente, o crack $(n=3)$ e a cola de sapateiro $(n=2)$ são consumidos apenas por usuários em tratamento compulsório.

Noto et al (1999), citando estudo do CEBRID realizado com estudantes da rede pública de ensino em capitais brasileiras, ressalta que as drogas psicotrópicas mais consumidas entre os jovens são os inalantes ou solventes ${ }^{4}$, em todas as regiões pesquisadas. No entanto, nos chamou a atenção em nossa pesquisa, que do total de 14 entrevistados, apenas dois referiram o uso da cola de sapateiro, conforme o quadro apresentado.

Embora, no contexto desta pesquisa, o álcool tenha sido a primeira droga usada pela maioria dos usuários entrevistados, exercendo, portanto, a função de "porta de entrada" para o uso de outras drogas, vale mencionar que dois usuários que consumiam maco-

3 Embora o problema do hábito de fumar, seja pouco enfatizado nas estatísticas oficiais vinculadas a dependência química, segundo os dados do INCA/MS, a dependência do tabaco é responsável por 85\% dos casos de Doença Pulmonar Obstrutiva Crônica (DPOC), 30\% dos casos de Câncer, 25\% dos casos de angina e Infarto Agudo do Miocárdio (IAM) e 25\% dos casos de doença cérebro-vascular (Brasil, 1998).

4 De acordo com Bastos e Cotrim (1998), inalantes ou solventes são nomes genéricos dados a inúmeros produtos industriais ou caseiros, dentre os quais destacam-se a cola de sapateiro, esmalte, acetona, lança-perfume, éter, a loló, gasolina e a benzina. 
nha afirmaram que nunca tinham usado o álcool antes, tendo sido a maconha, neste caso, a ponte para outras drogas, conforme o depoimento que se segue:

“...A maconha era o auge, né?...Eu viúva com 15 anos de idade, conheci pessoas de alto nível social, que foram quem me levaram a conhecer a droga. Tinha um colega lá em Mossoró que era muito ligado em drogas e depois veio a cocaína. A maconha já não fazia mais o mesmo efeito, e era muito rápido...” (UVA, F, 42)

Todavia, existem divergências e polêmicas entre os estudiosos sobre a questão da "porta de entrada" para algumas drogas, e segundo Silveira \& Silveira (1999), a afirmação de que o uso da maconha é o responsável pelo uso abusivo e pela dependência de outras drogas, pode soar como equivocada e, como consequência, levar o jovem a desconfiar da autoridade do "adulto", ao tentar conversar e alertar sobre os riscos do uso das drogas de forma aterrorizante. Além do que, ainda conforme os referidos autores, "essa afirmação pode aguçar a sua curiosidade, principalmente porque, para o adolescente, assumir riscos faz parte do jogo da vida, transformando o próprio risco em desafio" (p.74).

No caso da nossa pesquisa, essa passagem do uso da maconha para outras drogas não se constituiu numa condição linear e necessária para todos os participantes. Dois entrevistados que fazem uso da maconha, afirmaram que nunca experimentaram outras drogas ilícitas. Outro entrevistado, usuário de cocaína, revelou que nunca usou maconha antes, tendo começado a sua relação com as drogas através do álcool. Além destes casos, e em mais outros quatro usuários, foi o álcool que exerceu a função de "porta de entrada” para o uso abusivo de outras drogas. Como não há regulamentação efetiva da propaganda em relação ao tabaco e ao álcool, nem mesmo discussão sobre os danos à saúde advindos do seu uso, especialmente do segundo, é compreensível que ambos sejam uma espécie de convite ao consumo de outras substâncias.

Por último, outra constatação desta pesquisa, foi o fato de que do total dos (14) entrevistados, onze afirmaram fazer uso de mais uma droga, o que significa que a maioria dos usuários faz associação de duas ou mais drogas, o que do ponto de vista da saúde e da qualidade de vida é mais preocupante e mais danoso.

\section{Concepções dos usuários sobre o uso de drogas}

A discussão em torno das concepções dos usuários sobre o uso de drogas foi mais claramente evidenciada quando fizemos aos entrevistados a seguinte questão: “O que você pensa sobre o uso de drogas?". Os usuários deram as seguintes respostas:

1. Representa uma fuga dos problemas familiares e financeiros;

2. Prejudicial à saúde;

3. Falta de conhecimento sobre os riscos da dependência;

4. Insatisfação com a vida e a busca de prazer;

5. Um vício ${ }^{5}$;

6. Curiosidade;

7. Influência de amigos;

8. Destruição da vida do ser humano (fraqueza pessoal)

Assim, identificamos semelhanças nas concepções dos entrevistados sobre o uso de drogas, estivessem eles em tratamento ou de alta, sendo que alguns deles, principalmente os usuários que consomem álcool, relacionam e atribuem ao uso de drogas um valor negativo, como o fato de prejudicar a saúde e de ser "destrutivo em relação à vida do ser humano", de acordo com o depoimento:

"A pessoa quando se envolve com drogas não tem idéia do que vai se envolver, mas na realidade quando se envolve, fica difícil para sair, porque a droga deixa a pessoa viciada, é um vício. Eu falava, vou deixar, mas sempre chegava um amigo convidava e a vontade falava mais alto". (UTV, M, 23)

Outros entrevistados entendem, todavia, que o uso de drogas, traz tranqüilidade e sensação de bem-estar, ou seja, é atribuído um valor positivo associado à sensação de prazer, passando a droga passa a ser vista como um importante "suporte" para convivência com os vários problemas e dificuldades que a vida lhes impõe, conforme o depoimento a seguir:

"É uma insatisfação pessoal, é uma fuga da reali-

\footnotetext{
5 A Organização Mundial de Saúde (OMS) define a dependência de drogas, em substituição ao termo vício, "como um estado de adaptação mental e ou física à droga consumida regularmente, ou seja, quando uma pessoa não mais consegue alcançar seu bem estar ou executar tarefas cotidianas sem o auxílio de alguma substância psicoativa” (Brasil, 1998).
} 
dade, talvez sejam pessoas que não tenham conseguido alguma coisa a mais que ela queria na vida. a falta de objetivo, ou quando a pessoa se sente fracassado ela procura um paliativo...Eu comecei a usar na adolescência e tomava uma cerveja aqui e acolá, e fui me acostumando com a sensação prazerosa que me dava, e começou aí. Quando eu estava me sentindo mal ou deprimida já ia tomar uma cerveja, e começou com freqüência”. (U.T.V, F, 37).

Além disso, os usuários entrevistados também fizeram referências importantes à influência dos amigos quando se iniciam no uso de drogas, conforme expressa o relato que se segue:

“...São os amigos, muita gente culpa o traficante, mas ele não sai de dentro da favela dele para ir oferecer na casa de ninguém, agora a pessoa anda com um amigo, e acredita que ele é um amigo, que é mais fraco do que ele, digo fisicamente foi minha perdição. Mesmo que a gente diga não, como eu cheguei a dizer: rapaz eu nunca fui, mas eu tinha admiração de ver ele daquele jeito, pronto, experimentei pela primeira vez com 12 anos de idade.. " (U.T.C.A, M, 38 ).

Assim, de um modo geral, nossa investigação apontou que na concepção dos entrevistados, o uso de drogas, apresenta, contraditoriamente, duas faces. Por um lado, ele parece "ajudar a suportar" os problemas da vida, além de proporcionar uma certa compensação que se manifesta através do prazer e, por outro lado, o uso de drogas pode levar à destruição da vida. O depoimento a seguir ilustra esta interpretação:

“...Eu estava usando porque a maconha é tranqüilizante, é muito bom. É tão bom que não presta. Eu ficava tranqüila, passei dois anos sem chorar por minha mãe e meu marido. Eu sai de casa, tive de enfrentar o mundo e a droga para mim era como se fosse um tranqüilizante, como se fosse um apoio, porque no momento em que eu pensava na minha família, na minha mãe, ou no meu pai, naquilo tudo que eu não tinha mais, depois a tristeza vinha e aí quando eu fumava eu conseguia ver tudo bem...A droga é pior coisa que tem na vida. A droga é um caminha sem volta, se a pessoa não tiver força de vontade e acima de tudo uma boa cabeça... porque hoje eu poderia nem está viva" (UTVA, F, 42).

Na concepção dos entrevistados, são múltiplas às motivações que contribuem para o uso das drogas, destacando-se conflitos pessoais; pressão do grupo social; dificuldades escolares e profissionais; busca de alternativa de vida; prazer; fuga, dentre outros, confirmando a complexidade e a multideterminação da problemática do uso de drogas. Contudo, nos chamou a atenção o fato dos usuários terem apontado a "fuga dos problemas" como o principal motivo que leva as pessoas a fazerem uso de drogas. Acreditamos que essa motivação decorre, em parte, do fato de que a sociedade vem cada vez mais imprimindo profundas modificações na vida das pessoas, produzindo, muitas vezes, sofrimento que se manifesta em termos individuais, grupais e coletivos; seja no mundo do trabalho, nos relacionamentos sociais, no casamento, família, dentre outros, conforme expressam os próprios usuários. Mais do que isso, tem promovido mudanças na forma que os indivíduos pensam e na forma como estabelecemos relações com os outros.

Concordamos com Velho (200o) que o tema da violência na sociedade brasileira, a qual podemos associar a questão do consumo de substâncias psicoativas, não é apenas determinada pela desigualdade social, mas pela existência de um "esvaziamento de conteúdos culturais, particularmente os éticos, no sistema de relações sociais" (p.17). Tal situação significa a difusão de uma cultura individualizante e impessoal e o enfraquecimento das redes de solidariedade dentro da família e nas comunidades.

Assim, embora quase a totalidade dos entrevistados reconheça a importância e o papel desempenhado pelo Programa em relação ao enfrentamento do problema do uso de drogas e dos problemas de saúde a ele associado, atribuem à "força de vontade" individual de cada um, como indispensável para conseguir os resultados que desejam alcançar, seja o de reduzir ou parar o uso de drogas.

De um modo geral, a percepção dos usuários acerca da dependência, nos permite inferir uma há uma leitura limitada da realidade social onde estão inseridos e sobre o papel que a droga desempenha neste contexto, em que pese sinalizarem várias situações relacionadas a estas duas importantes questões. Exemplo disso, foi um aspecto observado nas entrevistas que revelam representações construídas socialmente em torno das pessoas que usam drogas, são identificadas como "marginais", "fora da lei”, prevalecendo uma visão discriminatória e punitiva vinculando o uso de drogas a questão criminal.

A nosso ver, a problemática do consumo de subs- 
tâncias psicoativas e suas formas de enfrentamento, devem ser analisadas a partir das várias expressões das desigualdades da sociedade, as quais são historicamente produzidas. Tais desigualdades produzem diversas formas de sofrimento, exclusões, que interferem na qualidade de vida, inclusive no que se refere ao processo saúde-doença, requerendo, assim, intervenções que ultrapassem as práticas apenas de cunho curativo e individual, exigindo ações coletivas de condução política-institucional numa perspectiva de construção da cidadania e de busca de qualidade de vida.

\section{Considerações Finais}

Apesar da questão do uso de drogas exigir maiores reflexões, essa pesquisa indica, a partir das concepções dos usuários de um programa público, que a tentativa de compreender e ajudar profissionalmente uma pessoa que recorre às drogas deverá passar necessariamente, como já dissemos, pela compreensão da sociedade na qual está inserida, sua posição na mesma, bem como a função que a droga aí desempenha e, sobretudo, por uma análise e abordagem multidimensional apropriada ao complexo fenômeno.

Além disso, essa pesquisa poderá ser uma importante contribuição aos profissionais que atuam na área de dependência, por refletir uma experiência em um serviço público, que evidencia a necessidade do conhecimento e uma maior reflexão sobre diferentes aportes teórico-metodológicos sobre o tema, bem como em relação aos seus objetivos, que não devem se restringir única e exclusivamente à busca da abstinência das drogas e sim da melhoria da assistência prestada no enfrentamento dos problemas associados ao uso de drogas, pautada no compromisso técnico, ético-político com as principais necessidades e interesses dos usuários.

Por fim, sem nenhuma pretensão de ensaiarmos conclusões gerais a partir dessa pesquisa, a partir do que anda nas bocas, e, principalmente, nas cabeças dos usuários de drogas que entrevistamos, entendemos ser bastante razoável afirmar que "não basta dizer não às drogas". Qualquer trabalho desenvolvido no campo da dependência envolvendo prevenção, educação e tratamento, numa perspectiva crítica e de qua- lidade de vida, requer que nos afastemos o máximo possível dos preconceitos e dos estigmas que contribuem para aumentar a exclusão social e podem nos levar a tomar medidas equivocadas que não favorecem o enfrentamento da problemática. Nessa perspectiva, requer práticas que além da capacidade técnica, incorporem uma dimensão humana, um compromisso ético-político com a valorização da vida e a construção de uma sociedade mais igualitária na busca da inclusão social.

\section{Referências Bibliográficas}

AMARANTE, Paulo (Coord.) Loucos pela vida: a trajetória da reforma psiquiátrica no Brasil. Rio de Janeiro: Fiocruz, 1995. 136p.

BASTOS, F. I.; COTRIM, B. C. O consumo de substâncias psicoativas entre os jovens brasileiros: dados, danos e algumas propostas. In: JOVENS acontecendo na trilha das políticas públicas. Brasília: CNPD, 1998. v.2. p.645-670.

BUCHER, R. Drogas e drogadição no Brasil. Porto Alegre: Artes Médicas, 1994.

BRASIL. Ministério da Saúde. Normas e procedimentos na abordagem do alcoolismo. 2. ed. Brasília, 1994. 59p.

__-. Relatório final da $2^{a}$. Conferência Nacional de Saúde Mental. 2 ed. Brasília, 1994. 63p.

Elaboração de proposta para normalização de serviços de atenção a transtornos por uso e abuso de substância psicoativa: exposição de motivos. Brasília. 1998. 17 p. Mimeo.

_-_. Temas de saúde mental: textos básicos CBAD. Brasília, 1998. p. 71-74.

_... Morbidade hospitalar do SUS: CID 10 no Rio Grande do Norte. Brasília, 20oo. Disponível em: <http:// www.datasus.gov>. Acesso em 16 out. 2000.

CABALLERO, A. Os inimigos da legalização da droga. Democracia, Rio de Janeiro, v.10, n. 104, p.15-18, jul/ ago.1994.

CENTRO Brasileiro de Informação sobre Drogas Psicotrópicas. Disponível em: <www.aids.gov.br/ drogas/bebidas.htm>. Acesso em: 5 nov. 2000. 
CRIVES, M. N. dos S. Análise do programa de prevenção e tratamento de alcoolismo e outras dependências em Natal/RN: o que pensam os usuários? Natal, 2001. Monografia (Especialização em saúde pública) - Universidade Federal do Rio Grande do Norte.

MARIA, J. (org.). Levantamento dos dados em 83 prontuários do programa de saúde mental. Natal: Secretaria Municipal de Saúde de Natal/Centro de Saúde de Pirangi, 1998. Mimeo.

MINAYO, M. C. de S. O desafio do conhecimento: pesquisa qualitativa em saúde. São Paulo: HUCITEC; Rio de Janeiro: ABRASCO, 1992. 269 p.

NATAL. Centro de Saúde de Pirangi. Normatização do Programa de Saúde Mental: ambulatório de dependência Química. Natal, 1999. Mimeo.

PRESIDÊNCIA DA REPÚBLICA. Secretaria Nacional Anti-drogas. Relatório do $1^{\circ}$ Fórum Nacional Antidrogas. Brasília, 1998. p.12-14.

NICASTRI, S. As drogas e seus efeitos. In: SEIDL, E. M. F.; COSTA, L. F.; SUDBRACK, M. de F. O (org.) Prevenção ao uso indevido de drogas: diga sim à vida. Brasília: Secretaria Nacional Anti-drogas/ Universidade de Brasília, 1999. p. 23-36.

NOTO, A. R.; GALDURÓZ, J. C. F.; NAPPO, S. O consumo de drogas psicotrópicas na sociedade brasileira. In: SEIDL, E. M. F.; COSTA, L. F.; SUDBRACK, M. de F.
O (org.) Prevenção ao uso indevido de drogas: diga sim à vida. Brasília: Secretaria Nacional Antidrogas/Universidade de Brasília, 1999. p. 37-46.

SEIDL, E. M. F.; COSTA, L. F. As drogas na atualidade. In: SEIDL, E. M. F.; COSTA, L. F.; SUDBRACK, M. de F. O (org.) Prevenção ao uso indevido de drogas: diga sim à vida. Brasília: Secretaria Nacional Antidrogas/Universidade de Brasília, 1999. p.15-22.

SEIDL, E. M. F.; COSTA, L. F.; SUDBRACK, M. de F. O (org.). Prevenção ao uso indevido de drogas: diga sim à vida. Brasília: Secretaria Nacional Antidrogas/Universidade de Brasília, 1999.

SILVEIRA, X. da S.; SILVEIRA, E. D. A família e as drogas. In: SEIDL, E. M. F.; COSTA, L. F.; SUDBRACK, M. de F. O (org.) Prevenção ao uso indevido de drogas: diga sim à vida. Brasília: Secretaria Nacional Anti-drogas/Universidade de Brasília, 1999. p.69-78.

VARA, C. A. Volver al Território. Psiquiatría Pública, Madrid, v.10, n.6, p.10-13, Nov/Dic.1998.

VELHO, G. Violência, reciprocidade e desigualdade: uma perspectiva antropológica. In: Velho, G.; Alvito, M. (org.). Cidadania e violência. Rio de Janeiro: UFRJ/Editora FGV, 200o. p.11-25.

WAISELFISZ, J. J. (coord). Juventude, violência e cidadania: os jovens de Brasília. São Paulo: Cortez, 1998.

Recebido em: 18/09/2002

Aprovado em: 02/06/2003 